\title{
El espacio para una nueva forma de pensar nuestra economía
}

\author{
Felipe Mardones Cruzat \\ Economía Sagrada, San Cristóbal de las Casas, México \\ Email: felipe.mardones4@gmail.com
}

\begin{abstract}
Resumen: Para construir una nueva visión de economía no es en absoluto suficiente mejorar las metas e intenciones de nuestro sistema y comportamiento humano, y mantener las metodologías subyacentes para alcanzar un mejor sistema. En este ensayo intento remover el contexto cultural -y organización neuronal inconsciente- de la separación. Solo al remover este contexto es posible verdaderamente abrir el espacio para una nueva manera de pensar la economía, desde un nuevo arreglo neuronal o narrativa del inter-ser. Para lograr este objetivo, propongo una mirada del pensamiento económico convencional donde éste no tiene fallas éticas ni de inteligencia, sino que no es más que un reflejo de la concepción del ser separado.
\end{abstract}

Palabras claves: separación, inter-ser, contexto cultural, narrativa subyacente, arreglo neuronal específico.

\section{The space for a new way of thinking economics}

\begin{abstract}
To be able to build a new vision of economics it is not at all sufficient to improve upon the goals and intentions of our current system and human behavior, while keeping the same underlying methodologies to reach a better system. In this essay I attempt to remove the cultural context -and unconscious collective array of neurons- of separation. Only by removing this context is it truly possible to open the space for a new way to think our economy, from a new neurons' array we can call the narrative of inter-being. To achieve this goal, I propose examining conventional economic thought in such a way that it does not miss ethical integrity nor intelligence, while showing that it is nothing but a reflection of the separate conception of being.
\end{abstract}

Keywords: Separation, inter-being, cultural context, underlying narrative, specific neurons’ array

\section{O espaço para uma nova forma de pensar nossa economia}

Resumo: Para construir uma nova visão da economia não é em absoluto suficiente melhorar as metas e intenções de nosso sistema e comportamento humano, e manter as metodologias subjacentes para alcançar um melhor sistema. Neste ensaio pretendo remover o contexto cultural -e organização neuronal inconscienteda separação. Somente ao remover este contexto é possível verdadeiramente abrir o espaço para uma nova maneira de pensar a economia, desde um novo arranjo neuronal ou narrativa do inter-ser. Para alcançar este objetivo, proponho um olhar do pensamento econômico convencional onde ele não tem falhas éticas nem de inteligência, mas como um reflexo da concepção do ser separado. 
Palavras-chaves: separação, inter-ser, contexto cultural, narrativa subjacente, arranjo neuronal específico.

$$
* * *
$$

\section{El libreto de "los buenos contra los malos" en la narrativa de la separación}

Hasta ahora, como economista comprometido en crear una nueva forma de habitar y relacionarnos entre nosotros y con la naturaleza, lo que más echo de menos es que en nuestras conversaciones haya espacio verdadero para lo nuevo. Me urge, con toda la fuerza de mi alma, el espacio para que en un artículo académico pueda yo hablar desde el sentimiento sincero y vulnerable de mi ser, en lugar de conversar sobre la economía como un fenómeno abstracto, ajeno, separado de mí. Digamos, un objeto que puedo describir en una pizarra o en un libro, que supuestamente no tiene nada que ver con lo que me ha pasado hoy día en mi vida tal y como de verdad es. Me urge este espacio porque de lo contrario me falta el aire, me ahogo antela exigencia de pensar con máxima inteligencia (que imagino que otros me imponen y que temo ante la posibilidad de no ser plenamente capaz de satisfacer). Me ahoga ese aferrarse a la frialdad de la razón que limita la posibilidad de expresarse. Porque lo que ansío expresar está fuera de lo posible en el contexto actual, pero se hace posible dentro de un nuevo contexto.

El espacio para cuestionar incluso y sobre todo cuál es nuestra concepción del Ser, porque ni siquiera eso está separado de nuestra realidad económica, sino todo lo contrario: es la base más profunda del asunto. Lo demás, son meros síntomas. Porque mientras no sacudimos el contexto sobre el que nuestra sociedad está construida jamás seremos capaces de construir algo nuevo.

Sin duda alguna tanto yo como los lectores de esta revista tenemos muy claro que el sistema capitalista neoliberal imperante en el mundo hoy en día nos está conduciendo, digámoslo derechamente, a la autodestrucción. Y no es solamente lo destructivo lo que nos duele del capitalismo, sino que es también la fealdad, la deshumanización, la desacralización, la uniformización, la pérdida de lo único por un todo homogéneo y anónimo. El aporte que busco hacer a través de este ensayo es que el problema con nuestro sistema económico es más profundo que un tema ideológico, es más profundo que un tema de relacionarse con la naturaleza como si fuese una fuente de recursos a explotar. Existe, más profundamente, un contexto cultural, una narrativa subyacente, un arreglo colectivo específico de neuronas que forma la base y sustento de nuestro sistema económico y modo de vida moderno. Este arreglo colectivo de neuronas es en realidad una forma específica de pensar, es decir de usar nuestra mente humana, de la cual somos mayoritariamente inconscientes. 
El hecho que sea inconsciente es de sumo interés, toda vez que no es posible crear algo nuevo desde la misma organización neuronal. Para crear algo nuevo es necesario renovar también nuestro arreglo neuronal colectivo, nuestro contexto cultural inconsciente. La narrativa subyacente -y para nada obvia- desde la cual nos movemos a crear algo. En otras palabras, para crear algo verdaderamente nuevo no es en absoluto suficiente mejorar las metas o las intenciones de nuestro sistema y comportamiento humano.

Es común escuchar críticas de todo tipo hacia la ciencia económica. Lógicamente, muchas críticas son bastantes duras y bien fundamentadas. Por muy legítimas y bien fundamentadas que sean las críticas, existe siempre un aspecto emocional expresándose inseparablemente, y tenemos por cierto todo el derecho a la indignación. Hoy en día,en efecto, nombrar la frase "capitalismo neoliberal” es equivalente a nombrar al "diablo" en el contexto religioso. No es casualidad que hayamos reemplazado la creencia dogmática religiosa de hace, digamos, un par de siglos atrás, con una creencia igualmente dogmática en la razón. Si en una cultura de fe en un Dios castigador el "diablo” representa la maldad, en una cultura de fe en la Razón humana el "capitalismo neoliberal” representa lo mismo: la maldad.

No es casualidad, tampoco, que en ambas culturas lo que más hay es “maldad”. En la cultura religiosa convencional lo que más hay es: culpa por maldad perpetrada por uno mismo, miedo por la permanente amenaza de mayores maldades que seguramente uno es capaz de cometer, y terror porque evidentemente vivimos rodeados de seres igualmente o más capaces de terribles maldades.

En nuestra cultural racionalista actual, lo que más hay es: ¡capitalismo neoliberal! Parece como una peste imparable que brota por todas partes, hasta en Cuba (y para qué hablar de China). ¿Existe algo que la pueda detener? Cuál sacerdotes que tienen las llaves del reino, los brillantes intelectuales que tenemos las llaves de la razón intentamos decirles a los fieles cuál es el verdadero camino.

Lo absurdo es que los sacerdotes intelectuales tenemos los mismos privilegios capitalistas que los sacerdotes religiosos. Somos súper burgueses salvo excepciones. Pero no es mi punto demostrar nuestra incoherencia, como si el hecho de ser coherentes lograra hacer emerger las verdaderas soluciones. Como si fuera necesario, al igual que en la cultura religiosa convencional, vivir permanentemente mejorándose a uno mismo, limpiándose de los pecados, pagando culpa por la maldad. Limpiándose del "capitalismo neoliberal” que uno lleva dentro.

En la cultura de fe en la Razón, si uno pone mucho de su parte, se educa disciplinadamente, lee muchísimos libros, piensa de manera independiente y con rigor, uno logra salir de la ignorancia. Se limpia del consumismo adictivo. Se limpia de ver televisión y creer ciegamente lo que dicen los medios evidentemente al servicio de los intereses del capitalismo. Sólo 
entonces uno se escandaliza al ver la verdadera magnitud de la corrupción del sistema, donde la mayoría de la población son ovejas, esclavos sumisos y ignorantes, al servicio de que unos pocos puedan enriquecerse. En ese momento, uno puede al fin y con todo derecho declararse limpio de "capitalismo neoliberal”. De ahí en adelante, la maldad está en otros, y no en uno mismo. Eso es un gran alivio para nuestro inconsciente educado por la religión y convencido de que fuimos concebidos con maldad, es decir, que venimos con fallas de fábrica (me refiero derechamente a la fábrica divina).

En resumen, ambas culturas, la de Fe en Dios y la de Fe en la Razón son sumamente similares. Tienen en realidad el mismo arreglo neuronal subyacente.En este artículo propongo una mirada inaceptable, incluso inmoral. Propongo que el capitalismo neoliberal no ha sido desarrollado, ni indoctrinado, con intenciones maquiavélicas de dominación y abuso. Sino que más bien, el capitalismo es consecuencia natural de la concepción del Ser en nuestra cultura. Cultura que no es sólo moderna, ni es sólo humana. Se trata de la concepción del Ser separado, la que ha sido extensa y brillantemente expuesta por Charles Eisenstein en su libro The ascent of humanity. En este libro Eisenstein rastrea el origen histórico del fenómeno de la separación hasta el origen mismo de la vida y pone en evidencia todas sus manifestaciones, que han ido aumentando en intensidad hasta el día de hoy.

Si uno se concibe a sí mismo como un ser discreto y separado, que convive con un montón de otros seres también separados, en un universo que también es separado, si uno acepta esa concepción de la vida (y lo hemos hecho a nivel neuronal querámoslo o no), pues evidentemente que todo lo que me rodea es a lo sumo indiferente hacia mi persona, y posiblemente sea hostil. De tal manera que mi respuesta natural es intentar controlar lo que más pueda las fuerzas adversas de la naturaleza. Si el universo es a lo sumo indiferente y quizás hostil, no hay garantías de que haya suficiente para todos; si además no hay garantías de que tu tengas algo que ver conmigo, aun cuando en ocasiones hemos cooperado el uno con el otro, tarde o temprano nos vemos en la obligación de competir el uno con el otro. Esto ocurre incluso antes de que se forme la institución del mercado: en esta concepción del Ser ya está la semilla de la competencia, ya está la semilla del famoso paradigma racional-egoísta del pensamiento económico. Entonces el desarrollo histórico a nivel ideológico e institucional del capitalismo neoliberal, era sencillamente cosa de tiempo. Iba a ocurrir tarde o temprano. Si no lo desarrollaban unos, lo desarrollarían otros.

Estoy diciendo, derechamente, algo completamente inapropiado de decir: estoy diciendo que no hay "maldad" en el capitalismo neoliberal. Seguramente leer esto será motivo de indignación: ¿acaso estoy defendiendo a quienes saben muy bien lo que hacen cuando abusan de su poder? ¿Acaso soy ingenuo o indiferente o aislado de las situaciones dramáticas y terribles, incluso guerras, todas a causa del capitalismo neoliberal? Entiendo la necesidad legítima de denunciar el capitalismo neoliberal, denunciar la indoctrinación, la base ideológica de tanto abuso y corrupción. Solidarizo con ella. Estoy diciendo que vale la pena ir más profundo. Mientras uno no 
se cambia de historia no se da cuenta que otra historia es posible. Desde la antigua historia de separación, nada de lo que digo hace sentido; de modo que si no te interesa contemplar un cambio de historia, un cambio de organización neuronal inconsciente, entonces todo lo que digo te parecerá un disparate.

La concepción del Ser que hemos adoptado como civilización, es para bien o para mal, la base más profunda generadora de realidades, generadores de ideologías, generadora por cierto de instituciones sociales. Generadora así mismo de nuestra obsesióncivilizatoria con el progreso tecnológico y económico. En verdad nunca hemos sido títeres de una élite poderosa que maneja el destino de nuestra civilización. Sino que incluso esta élite ha funcionado como un medio para que la experiencia de la separación se manifestara de tantas maneras y con creciente intensidad, hasta el día de hoy. El verdadero y único titiritero es la separación misma.

Sabemos, al menos intuimos con plena certeza, la pronta muerte de nuestra civilización cimentada en la separación. La concepción del ser que está naciendo, que siempre ha sido, y que ha adelantado -no exclusivamente-el budista zen Thich Nhat Hanh, es la del inter-ser. En ella, no es que yo soy junto contigo, sino que tú y yo “inter-somos”. Es decir, que tu ser está dentro de mi ser, y que yo estoy dentro de todo otro ser. Que el universo está dentro de mí y que yo estoy en el universo también. Por lo tanto, en esta concepción del ser, los dueños de Monsanto y de cada gran corporación, los ideólogos del capitalismo, los políticos corruptos, todos están dentro de mí. Eso no significa que haya una maldad dentro de mí que me hace falta reconocer, sino más profundamente que la maldad no existe, es una ilusión ${ }^{1}$.

Vivimos esencialmente una cultura de separación, donde necesariamente unos somos mejores que otros en cuanto a virtud, en cuanto a bondad. Donde es imposible que seamos iguales. Y uno vive en la permanente batalla interna por pertenecer al bando de los buenos, y otros son los malos. A menudo uno sencillamente se cuenta una historia por dentro, inconscientemente, para convencerse que uno es bueno, y otros son malos. Otras veces, uno sufre intensamente porque duda de su propia bondad. Algunos somos arrogantemente libres de maldad (¡aunque más profundamente es cierto!), o en virtud de nuestro mérito personal hemos logrado superar gran parte de nuestra maldad innata. Otros, en cambio, no han hecho suficiente mérito, no son tan virtuosos como nosotros, o bien vienen todavía con más fallas de fábrica que nosotros. [Evidentemente tengo que usar un lenguaje sarcástico que me permita resaltar el absurdo].

Abundan las críticas al paradigma económico convencional que señalan las fallas éticas y las faltas de inteligencia en el pensamiento económico. Sin embargo, en mi experiencia esas críticas sencillamente no son útiles. Estas críticas, evidentemente, no logran ni jamás lograrán gatillar una revisión del paradigma económico por parte de sus practicantes y defensores. ¿Por qué? 
1) En primer lugar, la razón humana puede usarse seriamente, legítimamente, para defender lo que sea que uno quiere defender. Si uno realmente (realmente) se para en los zapatos del otro, se da cuenta que su pensamiento no es nada de tonto, ni poco ético.

2) Nadie se abre a escuchar algo que viene con una violencia. La violencia de decirle "hay algo malo en ti", o "eres tonto". Más profundamente, ningún cambio verdadero, ninguna revolución profunda es posible desde esa violencia. Obviamente, no es posible construir paz usando como medio la violencia.

3) En efecto, si uno investiga seria y cuidadosamente, si realmente se da ese trabajo, descubre estas dos cosas. En primer lugar, el pensamiento económico convencional (por mucho que no nos guste), no es nada de tonto, en realidad es brillante. Las más brillantes mentes se han dedicado a desarrollarlo de hecho. En segundo lugar, el pensamiento económico convencional, incluido el capitalismo neoliberal, tampoco padece fallas éticas. Ya sé, muchos consideran inaceptable que yo diga esto que estoy diciendo, y lo digo con toda responsabilidad.

El problema más de fondo es que estando dentro de una narrativa subyacente, uno solamente es capaz de ver aquello que concuerda con la narrativa. No se trata solamente de ser "abierto de mente" para darse cuenta de ciertas cosas. Vivimos en una narrativa de "buenos y malos" que comenzó con la religión, continúo con las películas de los buenos luchando y venciendo a los malos (una y otra vez lo mismo), y llegó hasta nuestro momento actual donde para muchos "los malos" son los grandes empresarios como Monsanto, y los políticos en su poder oscuro y corrupto. Y para más encima vivimos con la ilusión de que algún día venceremos contra el mal, derrotaremos a todas las Monsanto y nos desharemos de todos los políticos corruptos. Porque, supuestamente, nuestra civilización funcionaría perfectamente bien si nos libráramos de la corrupción, de la ambición, y de la falta de inteligencia de algunos. ¿¿ no? ¡Por supuesto que no!

Esa narrativa de "buenos y malos" es la misma narrativa donde uno se castiga permanentemente a uno mismo, siempre buscando y encontrando algo malo dentro de uno. Adivina qué, siempre se puede encontrar lo que uno busca. Como ya mencioné: mientras no te cambias de historia no te das cuenta que otra historia es posible.

\section{El aporte de Federico Aguilera Klink en Polis, Revista Latinoamericana $\mathbf{N}^{\circ} 41$}

En esta sección me apoyo en el artículo de Aguilera "Economía y naturaleza humana, volviendo a Smith y Marx" publicado en Polis 41, el cual me parece un trabajo indispensable. Siendo yo un economista que estudié muchísimos años (Universidad Católica de Chile, University of Minnesota 
y finalmente University of Chicago), al regresar a Chile lo que más me indignó fue precisamente el fenómeno de la indoctrinación. ¿Cómo es posible que a través de fórmulas, gráficos y modelos se va inculcando un set de creencias en los estudiantes? Creencias que no tienen nada que ver con hechos científicos, creencias que nítidamente hacen daño a la sociedad humana y hacen daño a los mismos estudiantes, sin ellos siquiera darse cuenta. Esta denuncia, que hace brillantemente Aguilera en este artículo, es sin lugar a dudas necesaria y urgente. De hecho, confieso que por varios años yo mismo intenté sin éxito escribir justamente un artículo como el que ha escrito Aguilera. Al menos los estudiantes deben saber que existe un cuestionamiento serio, que lo que les enseñan como verdades absolutas no son tales.

Indispensable distinguir entre creencias adoptadas por la conveniencia de una ideología, y hechos científicos indisputables. Pero: eso es si uno acepta que existen los hechos científicos, supuesta verdad que es de por si cuestionable. En gran parte de nuestras verdades y hechos científicos (en todos en realidad), existe necesariamente una carga emocional que urge hacer consciente. Ocurre además, que toda abstracción del fenómeno de la vida es necesariamente incompleta e imperfecta, sencillamente porque estamos habituados al uso lineal de la mente humana, y el fenómeno de la vida es enteramente no lineal. Entonces toda verdad, especialmente las verdades complejas sobre nuestro entorno, son en realidad y necesariamente una reducción. Una reducción que uno elige cultural y emocionalmente, según sean nuestras preferencias (pero nunca objetivamente como ilusoriamente creemos).

Más profundamente y más de mi interés, es el siguiente hecho fundamental. Dentro de una sub-narrativa cultural específica, es decir de un arreglo neuronal específico, existen por cierto y es posible distinguir hechos científicos claros, indisputables. Y dentro de otra sub-narrativa ligeramente diferente existen otros hechos científicos indisputables, claros. Ambos conjuntos de hechos científicos son totalmente incongruentes entre sí. ¿Por qué? Porque siempre es posible usar la ciencia y la razón lineal adentro de cualquier sub-narrativa cultural. Por eso que es imposible que haya un vencedor en la batalla por tener la razón, cuando los contrincantes habitan en distintas sub-narrativas culturales. Por eso que es interesantísimo examinar con la consciencia cuál es la narrativa que subyace a ambas subnarrativas.Entonces, al conocer yo desde dentro la sub-cultura de los economistas, pude darme cuenta que, adentro de su propia narrativa y subcultura, no existe tal indoctrinación. No existe falta de integridad ni de inteligencia en sus postulados ni en su manera de pensar la economía. Ya lo sé, esto será inmensamente difícil de aceptar para el lector, toda vez que el lector se encuentre habitando una sub-narrativa diferente.

Ya en el comienzo de su artículo Aguilera cita a De Waal: "Los estudiosos del derecho, la economía y la política carecen de herramientas para contemplar su propia sociedad con objetividad. Raramente consultan el amplio conocimiento del comportamiento humano acumulado por la antro- 
pología, la psicología, la biología o la neurología...”(De Waal 2011 citado por Aguilera 2015: 1). (La negrita es mía). No obstante simpatizo con la observación de que los economistas ganarían mucho si realmente escucharán los aportes de otras sub-narrativas, discrepo notablemente en que siquiera exista tal objetividad. De hecho, considero que todos sin excepción tenemos mucho que ganar si realmente escuchamos al otro como un legítimo otro, como dice Humberto Maturana.

Describe Aguilera al agente racional como "el que sigue un comportamiento maximizador sin sentimientos ni valores morales que, además, ignora las relaciones con el medio ambiente y se olvida de que dependemos de él” (Aguilera 2015: 2). Este es un agente racional bastante irracional, ¿'se dan cuenta? ¿Quién podría considerar como racional a un agente tan completamente irracional? Evidentemente, adentro de la sub-narrativa del pensamiento económico convencional el paradigma racional se mira de otra manera (más adelante reflexiono sobre este punto).

Presentada como "ley de la naturaleza" (Schirrmacher 2014 citado por Aguilera 2015: 2) o como sea, la afirmación de que el ser humano es egoísta es en realidad una expresión, una manifestación más, de la concepción del Ser separado. Por eso que no es accidente que en la biología evolutiva se haya adoptado también la mirada de que el gen es un ente egoísta ocupado únicamente con su propia sobrevivencia. Naturalmente, no queda otra salida que acusar: "Todos los tramperos disimulan sus trampas..." (Ibíd.). No existe otra mirada de los economistas que sea posible adentro de esta sub-narrativa.

Según Aguilera "las reglas (...) se suelen calificar de "intervención no deseable" excepto cuando esas reglas benefician al capital, es decir, a los poderosos”(Aguilera, 2015: 2). Mirado desde afuera evidentemente eso es lo que se observa: permanentemente, en crisis o no, los beneficiados por las decisiones de políticas públicas siempre son los poderosos y el capital. Sin embargo, mirado desde adentro, la realidad es otra: soy testigo de los intensos estudios e iniciativas honestas que buscan beneficiar al pueblo, que buscan por ejemplo igualdad de oportunidades y una distribución equitativa de la riqueza. Lo que pasa es lo que Ud. y yo sentimos desde afuera, es que esos objetivos jamás se van a lograr adentro de la narrativa común de separación. No sólo adentro de la sub-narrativa económica convencional no existe solución posible, en la sub-narrativa anticapitalista (y desde luego separada) tampoco existirán jamás las verdaderas y profundas soluciones que requerimos.

En la narrativa anti-capitalista existe también un dejo de ingenuidad: el ver repetidamente, una y otra vez, a todos los economistas como personas con malas intenciones, que sólo les interesa el capital y el poder de los poderosos. A la vez, es ver la vida de una manera terriblemente pesimista, puesto que si adoptas esa sub-narrativa no te queda otra alternativa que observar a la mayoría de la gente subyugada, impotente, incapaz, mientras la visión preponderante y ganadora, en permanente ascenso, es la capitalis- 
ta neoliberal, sin importar los esfuerzos inagotables de nosotros los intelectuales anti-capitalismo.

Mishan, citado por Aguilera, observa que existe una "necesidad de un cambio radical en la manera habitual de observar los acontecimientos económicos”(Mishan 1971 citado por Aguilera 2015: 2). Y Aguilera agrega: "se trata de trabajar hacia el objetivo de la integración frente a la situación actual de completa disociación”(Aguilera 2015: 2). Exactamente, hablamos de un cambio radical: se trata de disolver la ilusión de la separación. Y es sumamente interesante observar que la observación de la separación como contexto cultural viene surgiendo por todas partes (por ejemplo el mismo Aguilera y muchos otros han observado la ilusión de separación humana y económica de la naturaleza). Quisiera Aguilera que el pensamiento del "economista vaya a favor de los seres humanos y de la comunidad, lo contrario es lo que estamos viviendo actualmente, basado en la violencia, y sólo nos lleva a más violencia y más sufrimiento en la mayoría de los países y para la mayoría de las personas” (Ibíd.). Lo único que falta incluir en su bello y sincero deseo de paz y no-violencia, es a los propios economistas.

¿Por qué las múltiples advertencias sobre la economía disociada que vivimos han sido sistemáticamente ignoradas o descalificadas? Hasta ahora, la respuesta ofrecida ha sido esencialmente ética, es decir, que los economistas, practicantes y defensores de esta economía disociada sencillamente tienen maldad dentro suyo. La respuesta de este ensayo es nueva: estas advertencias son ignoradas o descalificadas porque no hacen sentido adentro de la sub-narrativa de la economía convencional, y además porque vienen con una violencia, una superioridad, que no ayuda a abrir las puertas al escuchar.

La economía disociada ha creído ciega y disparatadamente que ofrece una "racionalidad universal" (Aguilera 2015: 3). Efectivamente, yo también he observado lo mismo: así lo cree la economía disociada adentro de su sub-narrativa. ¡Así lo creía yo cuando me encontraba adentro de esta subnarrativa! (Es tan hermosa esa racionalidad del paradigma económico convencional que yo estaba perdidamente enamorado de ella). Pero es necesario que el observador tenga su propia idea de "racionalidad universal" para ser capaz de hacer esta observación.

Como dice Galbraith recogido por Aguilera, el fraude de la economía es inocente, "quienes participan en él no lo reconocen explícitamente como tal...” (Galbraith 2004 citado por Aguilera 2015: 4). Totalmente de acuerdo. Adentro de su propia narrativa, el fraude no es fraude. Aquí no estoy siendo sarcástico, sino efectivamente estoy diciendo que no es un fraude. (Eso es pararse en otra narrativa).

Me fascina la cita “...los profesionales de la salud mental trabajamos con personas que mantienen discursos con características semejantes” (Fernández 2013 citado por Aguilera, 2015: 4), en cuanto al comportamiento delirante de los economistas. Me fascina porque me interpreta la indigna- 
ción humorística. Me fascina porque yo por años he dado batalla para denunciar el delirio en otros, luchando para que me escuchen los que no quieren escucharme, sin ver mi propio delirio. $\mathrm{Y}$ me fascina puesto que el comportamiento delirante hace sentido toda vez que existe una realidad objetiva que el delirante ignora, niega. Pero si esa realidad objetiva se relativiza, queda en duda quién es realmente el delirante.

Si bien es cierto que el capitalismo favorece en sí mismo el desarrollo de un "hombre enajenado", mucho antes de que existiese el capitalismo ya estaba en desarrollo la enajenación de la humanidad, a través de su concepción del ser y de la vida separado.

\section{Abriendo espacio en el pensamiento económico convencional}

Intentaré aquí abrir el espacio para concebir, para relatar una narrativa donde el pensamiento económico convencional es inteligente y ético, por mucho que no nos guste. Abrir este espacio significa a la vez una mirada más profunda, que permite vislumbrar desde donde es posible crear algo nuevo: por supuesto, desde el inter-ser, y desde un nuevo arreglo neuronal, es decir una nueva forma de pensar.

Es cierto que el pensamiento económico convencional adoptó un supuesto que a muchos nos parece aborrecible: que el principal motivo que guía las decisiones de las personas es su interés individual, egoico. Ya lo dice De Waal citado por Aguilera, que "somos menos egoístas y menos racionales que lo que los economistas suponen que somos” (De Waal 2007 en Aguilera, 2015: 6). Todo tipo de argumentos perfectamente lógicos y evidentes se han desplegado para señalar el absurdo en tal supuesto. Sin embargo, los resultados no han sido los esperados. El uso de la fuerza de la razón no ha sido suficiente ni para cambiar las bases intelectuales de nuestra organización civilizatoria, ni mucho menos para detener la proliferación del capitalismo neoliberal por todas partes. Mayoritariamente, como humanidad, seguimos actuando cada uno de nosotros como si fuésemos un ser separado, en un universo preponderantemente hostil, donde posiblemente lo más seguro sea actuar compitiendo con los demás en beneficio propio o a lo sumo en beneficio de los más cercanos. Donde sí en determinado momento del día me pasa una circunstancia que me molesta, actúo desde la noción que debe ser porque la vida alrededor mío es indiferente u hostil hacia mí. Por ende mi reacción habitual será extremar mis medidas de precaución y de control para evitar las situaciones que me molestan. Y sin embargo cuando esas situaciones siguen repitiéndose y aumentando en intensidad, a pesar de todos mis esfuerzos por evitarlas, me empiezo a preguntar qué puedo hacer que sea diferente. ¿Qué tal confiar en la vida? En mi caso, cuando me aburrí de sufrir fue apenas cuando empecé a confiar realmente en la vida. 
En particular, como argumentaré más adelante, no es efectiva una crítica que señale la falsedad y absurdo del supuesto del comportamiento egoísta. Los economistas serios no creen que el comportamiento humano sea exclusivamente egoísta. Tampoco consideran que la búsqueda del bienestar personal sea por entero equivalente a egoísmo. Ni tampoco consideran que sus modelos sean necesariamente excluyentes del comportamiento compasivo o no egoísta. Sencillamente consideran que el paradigma racional basado en el auto-interés es un buen paradigma para entender el comportamiento mayoritario de la economía, para desarrollar modelos que tienen un alto poder analítico y un alto poder predictivo. En otras palabras, la crítica a la falsedad y absurdo del egoísmo en los postulados de la economía no es efectiva, no es recibida, no es realmente considerada.

Una revisión original del pensamiento económico convencional pasa por observar la creencia o fe religiosa en la razón. Mostrar el absurdo en ello muestra a la vez el absurdo en considerar que quienes defienden el sistema económico lo hacen por maldad o intereses personales poco honestos. Esa mirada es la absurda mirada donde el que mira es superior, más inteligente, mejor persona.

La fe religiosa en la razón tiene en adoración una forma específica de inteligencia que es la inteligencia lógica, lineal. Esta es una forma de inteligencia masculina: útil pero incompleta, apasionante pero incapaz de abarcar el fenómeno de la vida puesto que nuestra vida se manifiesta en una realidad fundamentalmente no lineal. La inteligencia masculina se caracteriza por considerar los fenómenos observados como externos, como realidades independientes al observador. Al universo lo ve como una constitución de bloques objetivos conformantes de la realidad física, unos sobre otros. En los ámbitos científicos convencionales es totalmente inaceptable que uno cuestione la realidad objetiva. Sin embargo, si uno escrutiniza con seriedad puede darse cuenta que esa supuesta condición objetiva del mundo externo no es más que una creencia cultural (hay muchos pensadores que vienen diciendo esto mismo, de distintas maneras, como por ejemplo Maturana y Varela). Una forma de ver el mundo, de pensar el mundo, que hace concordancia con nuestra cultura subyacente interna inconsciente, pero que no tiene por qué ser verdad.

\section{Enfoque de la ciencia económica en el bienestar material}

La ciencia económica es en su esencia el estudio del bienestar de la sociedad. Contrario a lo que comúnmente se cree, la ciencia económica no entiende el bienestar como un fenómeno exclusivamente material ni exclusivamente cuantitativo. El análisis económico no restringe su atención únicamente a bienes materiales. Puede incluir también bienes intangibles, tales como el estado de la calidad ambiental, o la belleza escénica generada por un bosque. Los economistas no ignoran que el bienestar o la felicidad es un fenómeno complejo, y que puede haber muchas cosas que la afecten. La ciencia económica equivoca el camino no porque sea exclusivamente cuan- 
titativa, sino porque es exclusivamente intelectual.

Sin embargo, de acuerdo al pensamiento económico es razonable concentrarse en el aspecto material del bienestar. Para ilustrar este punto, considérese un individuo racional cuyo ingreso ha sido aumentado, de manera tal que sus posibilidades de decisiones y acciones han aumentado. Ahora tiene un rango más amplio de posibles elecciones: tiene las mismas posibles elecciones que tenía antes del aumento de su ingreso, además de un conjunto de nuevas posibles elecciones. Por lo tanto, no puede ser que su bienestar haya decrecido. Después de todo, si el individuo así lo quiere puede todavía tomar la misma decisión que hubiese tomado antes del aumento del ingreso (puesto que ésta todavía es parte de las elecciones posibles). Por ende, se concluye que mientras más dinero un individuo tiene, mayor su nivel de bienestar. Esto se llama en jerga económica el Axioma Débil de Preferencias Reveladas (WARP por sus siglas en inglés).

Como consecuencia, los economistas consideran apropiado enfocar su atención en el aspecto material o cuantificable del bienestar. Por ejemplo, las políticas públicas que se supone sirven el bienestar general de toda la población son decididas en gran parte considerando de qué manera afectan positiva o negativamente el nivel de ingreso de las personas. Aquí mi punto es subrayar que esta línea de pensamiento es razonable. Que no es el problema de fondo el haber sido construida con malas intenciones, $\mathrm{o}$ que sea tonta.

Uno podría discutir las aristas sicológicas del Axioma Débil de Preferencias Reveladas. Por nombrar un ejemplo, que el hecho de tener nuevas alternativas posibles de elección puede constituir un motivo de stress o angustia. Pero dentro de esta narrativa ese tipo de aristas debiera ser superada por una persona racional, al menos a nivel evolutivo con el paso del tiempo. Una crítica más profunda sería observar el efecto de retroalimentación en el comportamiento. Es decir, si adoptamos una ciencia y una cultura que considera que tener un mayor nivel de ingreso está asociado a tener un mayor nivel de bienestar, ¿qué tipo de efectos tiene eso sobre el comportamiento de la gente común y corriente? Es bien obvio, que la búsqueda de la felicidad en nuestras sociedades de hoy en día está siendo encausada mayoritariamente a través de la búsqueda de aumentar el nivel de ingresos (para colmo, con muy malos resultados para una mayoría). En pocas palabras, una idolatrización y obsesión con tener más dinero. En fin, argumentos nos sobran para señalar qué mala idea es el dogma del bienestar material. No necesito insistir sobre ello en este escrito.

Más me interesa a mí, un punto mucho más sutil que siempre es pasado por alto. Se trata de la mirada separada de las cosas. La mirada de la separación como fenómeno cultural inconsciente. En el caso del Axioma Débil de Preferencias Reveladas, se considera que otras posibles consecuencias sobre la felicidad pueden ser hechas a un lado, toda vez que uno analiza por separado el bienestar material sin temor a equivocarse. El hecho mismo que nuestra mentalidad tienda a hacer una lista de las posibles varia- 
bles que afectan la felicidad es ya de por sí una manera de pensar lineal, separada, que deja afuera una riqueza de situaciones que escapan a la razón lineal. Ni siquiera un análisis que admita complejidad e interrelaciones de efectos es suficiente para captar la esencia de un fenómeno como la felicidad, que no solo es complejo, sino que yace más allá del lenguaje analítico. En otras palabras, cada vez que intentamos razonar analíticamente sobre la felicidad como si fuese un concepto su esencia se pierde, desaparece de la conversación.

En fin, hoy en día existe una concepción enraizada en nuestra cultura, según la cual para alcanzar la felicidad se necesita reunir dinero. Por ejemplo, cuando sentimos compasión por personas lo primero que pensamos es en darles dinero. O si alguien sufre un daño emocional la respuesta más común es compensar con dinero. Si nos importa el nivel de felicidad de nuestro país, pues nuestra respuesta racional es que nos interesa que el país crezca económicamente, es decir aumente su nivel de ingresos, y a la vez por supuesto nos importa que mejore la equidad en la distribución de los mismos. Llamo la atención sobre la frase nivel de felicidad, porque nuevamente evidencia nuestra obsesión por linealizar todo en la vida. Evidentemente, una conversación que considera a la felicidad como un fenómeno que tiene magnitud, niveles, es una conversación donde queda afuera lo más sutil y misterioso del fenómeno de la felicidad. Si pensamos que la felicidad es una cantidad, andamos perdidos como humanidad buscando aumentarla según la lista de factores que la afectan.

No es mi intención rechazar la riqueza material, ni tampoco desconocer las urgentes necesidades de gente que vive en miseria, al contrario. Mi punto es alumbrar nuestra obsesión con el dinero, como consecuencia profunda de nuestra mentalidad lineal y separada (y no una consecuencia de la ambición de algunos, la ambición es un mero síntoma más de la separación ${ }^{2}$ ).

\section{Idealización del comportamiento racional}

El paradigma racional del comportamiento es el supuesto básico en la ciencia económica convencional. Incluso en modelos económicos alternativos (la corriente conocida como Economía del Comportamiento) que reconocen la falta de racionalidad en la gente del mundo real, ello es visto implícitamentecomo una debilidad sicológica, que debiese ser superada al desarrollar nuestra inteligencia, sino por la misma evolución de nuestra especie. A propósito, los economistas no son tan ingenuos como para pensar que la gente real es plenamente racional, de hecho se han interesado por modelos de irracionalidad. Más bien, consideran que el paradigma racional del comportamiento es un buen paradigma para entender el comportamiento humano por su poder analítico y predictivo.

La cultura moderna mayoritariamente considera la racionalidad como una característica ideal del comportamiento humano. Se espera que a medi- 
da que la humanidad progrese, su comportamiento se acercará al comportamiento completamente racional. Esto rara vez es argumentado explícitamente, se considera tan obvio que ni siquiera está sujeto a discusión.

La idealización del paradigma racional del comportamiento humano es natural en una cultura de fe religiosa en la razón, que se caracteriza por ver el todo fragmentado, separado, y entender los fenómenos de manera lineal. También se caracteriza, nuestra cultura de fé en la razón, por estar convencida de que sabe mucho, y lo que no sabe es poco, o es relativamente fácil de abarcar por las estructuras y conceptos de lo ya conocido.

Es más, un entendimiento no-racional del comportamiento humano, adentro de una cultura de fe en la razón, es bastante extraño, es como un marciano en la Tierra. De hecho, tautológicamente los modelos de comportamiento racional funcionan a la perfección del punto de vista analítico (ipuesto que están dentro de su propio contexto!). En cambio los modelos que aceptan un comportamiento no-racional son débiles analíticamente. Es extraño entender el comportamiento no-racional en un contexto subyacente de fe en la razón, como si únicamente el observador fuese capaz de razonar mas no así quienes son observados por el observador.

El comportamiento racional sólo puede tener sentido adentro de lo conocido. Pero sin importar cuán grande nuestro conocimiento crezca, lo desconocido nunca decrecerá en magnitud. Lo desconocido es una presencia permanente en nuestra existencia. ¿Cómo podría nuestro comportamiento ser racional al enfrentarse a lo desconocido? Frecuentemente tenemos que tomar decisiones sin saber mucho acerca de las posibles consecuencias de nuestras acciones.

Los economistas consideran que se puede reducir lo desconocido a variables aleatorias con distribuciones de probabilidades. Incluso sus modelos más avanzados permiten distribuciones de probabilidades desconocidas, sobre las que el agente tomador de decisiones va aprendiendo en la medida que toma decisiones. Es decir, los economistas "no desconocen a lo desconocido”. Pero su enfoque de fe en la razón limita y reduce la extensión, la complejidad y el misterio de lo desconocido nuevamente a un fenómeno lineal, abarcable por la razón y los modelos. En la realidad, a menudo ni siquiera sabemos que existe un curso de acción por desenvolverse, que no es posible anticipar. Programados por la mentalidad lineal, obsesionada por lo que ya conoce, nos imaginamos un set de posibles acciones y a veces nos angustiamos porque dentro de todas las posibilidades que somos capaces de imaginar, no existe solución concebible. Más tarde, nos sorprendemos cuando aparecen nuevas posibilidades que antes era imposible imaginar. ¿Es este un fenómeno natural de la pasta misma del universo? ¿O es acaso una falta de racionalidad de nuestra parte, que vamos resolviendo al evolucionar y hacernos más inteligentes? Espero que este escrito sirva para considerar seriamente la primera respuesta. 
El comportamiento puramente racional es sencillamente irreal. Por ejemplo, para que el comportamiento sea acorde al paradigma racional, las decisiones tienen que ser consistentes, es decir, no estar sujetas a contradicciones entre ellas. Quienquiera que se conoce a sí mismo, sabe que no es nada difícil encontrar múltiples contradicciones en el comportamiento humano, incluso en personas que actúan con impecabilidad. Esto no es un error que necesite ser corregido. Se trata más profundamente del permanente movimiento del universo y la esencia femenina de la vida, siempre sujeta a cambios inesperados.

Usualmente las personas de espíritu despierto son acusados de ser idealistas o utópicos. Qué puede ser más idealista y utópico que un ser humano completamente racional.En resumen, es absurdo que un ser humano intente o valore hacerse plenamente racional. La existencia humana se mueve en la multidimensionalidad del universo, mientras que la razón está restringida a moverse linealmente. En todo caso, de por si somos seres absurdos que ilusoriamente nos vemos a nosotros mismos como si fuésemos coherentes y serios. No queda más que reírse de nosotros mismos.

\section{Sobre el Egoísmo}

Como dije antes, los economistas serios no creen que el comportamiento humano sea exclusivamente egoísta. Tampoco consideran que la búsqueda del bienestar personal sea por entero equivalente a egoísmo. $\mathrm{Ni}$ tampoco consideran que sus modelos sean necesariamente excluyentes del comportamiento compasivo o no egoísta. Sencillamente consideran que el paradigma racional basado en el auto-interés es un buen paradigma para entender el comportamiento mayoritario de la economía, para desarrollar modelos que tienen un alto poder analítico y un alto poder predictivo.

No obstante, el pensamiento económico científico considera el interés individual, de una u otra manera, como el determinante primordial del comportamiento humano. Sencillamente nuestra cultura pone demasiada fe en el concepto de que el individuo existe por sí mismo, nunca se ha detenido a contemplaruna noción de co-existencia. El ser humano es entendido por los modelos económicos como un individuo que toma sus decisiones de acuerdo a lo que sea más deseable para sí. Es decir, el ser humano toma sus decisiones de manera de aumentar su felicidad personal. Después de todo, ¿quién podría tomar una decisión que disminuya su felicidad? Nótese que visto de esta manera este es un raciocinio inofensivo. En otras palabras, si uno pone énfasis en la noción del individuo (cosa que es ineludible en una cultura donde el ser se concibe en separación), no tiene nada de extraño considerar que el ser humano toma sus decisiones a fin de aumentar su propia felicidad.

Un individuo hipotético adentro de un modelo económico convencional cualquiera puede perfectamente ser alguien compasivo, que le importa sinceramente la gente pobre y que le afecta el estado de la calidad 
ambiental; y aun así, puede perfectamente tomar sus decisiones a fin de aumentar su propia felicidad. En su caso su felicidad se afecta por más cosas que su propio nivel de consumo pero a fin de cuentas sigue siendo su propia felicidad. Después de todo, ¿quién podría tomar una decisión que disminuya su felicidad? Con esto quiero decir que lo que desde afuera vemos como egoísmo, desde adentro del pensamiento económico puede perfectamente no serlo. Más profundamente, el arreglo neuronal específico que concibe al ser separado, conlleva necesariamente a un entendimiento egoísta del ser humano. Uno puede vislumbrar que adentro de la concepción del ser separado no cabe otra cosa que el egoísmo. Por último, todo intento por racionalizar una mirada compasiva, cooperadora del ser humano que mantenga el paradigma de "tomar decisiones individuales a fin de aumentar la propia felicidad”, deja gusto a poco, toda vez que la esencia de la compasión se pierde adentro de la narrativa individualista del ser separado.

La compasión, sentimiento que siempre hemos intuido desde nuestras entrañas, solo hace sentido en la concepción del inter-ser.

En resumen, esta es una invitación a no culpar a los economistas porsuponer que somos más egoístas y más racionales de lo que en verdad somos. Y definitivamente esta invitación no nace por un intento de ser bondadoso hacia los economistas. Más profundamente, esta es una invitación hacia la nueva narrativa del inter-ser, que nace de la pasión por ser parte de la co-creación de un nuevo mundo.

Claramente a todos nos preocupa el egoísmo en nuestra civilización. Nos duele, nos molesta, nos daña el comportamiento egoísta de otras personas. Nos indigna que se legitime al egoísmo como si fuera una realidad científica del comportamiento humano. Y, si nos preocupa la presencia del egoísmo afuera nuestro, seguramente alguna preocupación hemos de tener acerca de nuestro propio egoísmo. Cuando declaramos que los humanos "somos menos egoístas que lo que suponen los economistas", pareciera ser que aceptamos que el egoísmo en nuestro comportamiento es inevitable. ¿Se trataría entonces de ser razonablemente egoístas, pero no tanto como los que abusan? Dentro de la concepción del ser separado ciertamente el egoísmo es inevitable. En una nueva historia del inter-ser, donde la maldad es ilusión, el egoísmo deja de ser algo que hay que evitar o controlar o derrotar dentro de uno mismo. El egoísmo pasa a ser algo completamente sano que es nada más y nada menos que el amor a uno mismo. Ese egoísmo no tiene ninguna necesidad de ser derrotado ni controlado. En la historia del inter-ser, el interés por los demás humanos (y por todas las formas de ser del universo) se funde con el interés propio, se hacen uno. O sea, en la historia del inter-ser nadie tiene que vencer a su propio egoísmo.

La forma de egoísmo que hoy en día observamos como dañina, abusiva, destructiva, tóxica no es una falla de fábrica del ser humano. Es un callo que formamos en la piel de nuestro ser, cuando frente a la experiencia traumática de la separación no supimos cómo confiar en la vida y tuvimos que buscar maneras de defendernos. Experiencia traumática que comenzó 
en el momento mismo de nuestro nacimiento a nivel personal, y que comenzó hace milenios a nivel cultural. Experiencia traumática que sana cuando se restituye la suave verdad de unión de la vida. 
Polis, Revista Latinoamericana, Volumen 15, $N^{\circ}$ 45, 2016

\section{Notas}

${ }^{1}$ La mirada de que en la vida la maldad no existe y es ilusión requiere una discusión extensa, seria y profunda. Refiero al lector al libro fundamental The more beautiful world our hearts know is possible, por Eisenstein. Este libro está escrito desde la misma visión del inter-ser.

${ }^{2}$ La mirada de la ambición como un síntoma más de la concepción del Ser separado está desarrollada en el libro Sacred economics, por Eisenstein, que además es un libro que vale la pena citar dado que está íntimamente ligado a este artículo (forma parte de la misma visión). 


\section{Bibliografía}

Aguilera, F. (2015), “Economía y naturaleza humana, volviendo a Smith y Marx”, en Polis $N^{\circ} 41$, Polis Revista Latinoamericana, Santiago.

Eisenstein, C. (2007), The ascent of humanity: civilization and the human sense of self, Evolver editions. Berkeley, Ca.

Idem (2011), Sacred economics. Evolver Editions, Berkeley, Ca.

Idem (2013), The more beautiful world our hearts know is possible. North atlantic books, Berkeley, Ca.

Maturana, H. y Varela, F. (2003), El árbol del conocimiento. Las bases biológicas del conocimiento humano, Lumen, Buenos Aires.

Nhat Hanh, T. (1999), Interbeing: Fourteen Guidelines for Engaged Buddhism, Parallax Press

Recibido: 28.10.16

Aceptado: 01.12.16 